\title{
SOME ASPECTS OF DEVELOPMENT AND APPLICATION OF THE BEARING-BOLT SUPPORTING TECHNOLOGY
}

\author{
Krukovskyi O.P.
}

Institute of Geotechnical Mechanics named by N. Poljakov of National Academy of Sciences of Ukraine, Corresponding member of NAS of Ukraine, Doctor of Technical Sciences, Deputy Director of the Institute, Ukraine

\section{Krukovska V.V.}

Institute of Geotechnical Mechanics named by N. Poljakov of National Academy of Sciences of Ukraine, Senior Researcher, Doctor of Technical Sciences, Senior Researcher in Department of Dynamic Effects of Rock Pressure Control, Ukraine

\section{Bulich Yu.Yu.}

Institute of Geotechnical Mechanics named by N. Poljakov of National Academy of Sciences of Ukraine, Researcher in Department of Rock Mechanics, Ukraine

\section{Zemlianaia Yu.V.}

Institute of Geotechnical Mechanics named by N. Poljakov of National Academy of Sciences of Ukraine, Chief technologist in Department of Rock Mechanics, Ukraine

\footnotetext{
Abstract. Geological and technical conditions in the most of Ukrainian mines are significantly more complicated than in the mines of other leading countries, which produced coal. A simple transition of the accumulated foreign experience of anchoring did not give any effective positive results. The goal of this investigation is to study more deeply mechanism of the roof-bolt operation and to specify the spacetime laws of geomechanical processes occurred in the system "edge rock - roof bolts". The research tasks are: to design a mathematic elastoplastic model for calculating stress state of the rocks around the roadway supported with the bolts; to explore support formation around the bolt in the mine roof; to establish a concept of the rock-bolt support interaction, according to which supports unite into a single construction that can resist rock pressure; to develop the bearing-bolt supporting technology and expand range of its application.

These tasks have been completely resolved. The technology of the reinforced and powerful bearing-bolt supporting designed by our Institute of Geotechnical Mechanics was successfully realized in practice in 52 Ukrainian mines for driving more than 700 preparatory roadways and permanent workings. This approach helped to achieve
} 
stable state of the roadways under the complicated mining and geological conditions and obtain good economic effect thanks to the cut expenses spent to the roadway supporting and repair.

Key words: anchoring, complicated mining and geological conditions, geomechanical processes, mine workings, numerical simulation, supporting technology.

\section{Introduction}

Maintaining of the mine roadways in stable operational state during the whole period of their exploitation is the most critical problems of the mining industry. Safety of miners, provision of working places with air and materials, productivity of the heading and mining machines, load on the longwalls, and, in whole, on the mine operation all of these issues depend on the safety roadway supporting. With increased depth of the coal seam development, rock stresses reach their maximum values; besides, rheological effects occur, which all together lead to great loads on support causing its deformation and rock displacement towards the roadway [1].

The commonly used arch supports do not provide resistance sufficient for essential reduce of deformation processes in the rocks around the roadways. During the last 25 years, bearing capacity of the yielding arch support has been improved by 2-2.5 times mainly due to higher steel intensity. Despite of this fact, a significant number of mine roadways equipped with the arch supports are in emergency state and require repair (fig. 1) because even the arch supports with high steel intensity are characterized by low bearing capacity, which does not exceed 1.5 MPa.

Expenditures to the support setting in the roadways are not limited by the factor of the steel intensity. They are added by the costs of the support transportation and installation. Significant weight of the arch support elements and low level of mechanization of process of their installation contribute to the increased injury risk during these works. Besides, due to the arch deformation, cross section of the roadways decreases: consequently, the situation is complicated by the dust-andgas mode, which worsens working conditions in the roadways [2]. In general, it can be stated that enormous financial inputs spent for securing the roadways by the arch supports do not ensure their keeping in a reliable operational condition and that traditional yielding arch supports are not able to fully compensate for the increasing displacements of the rocks into the roadways. 


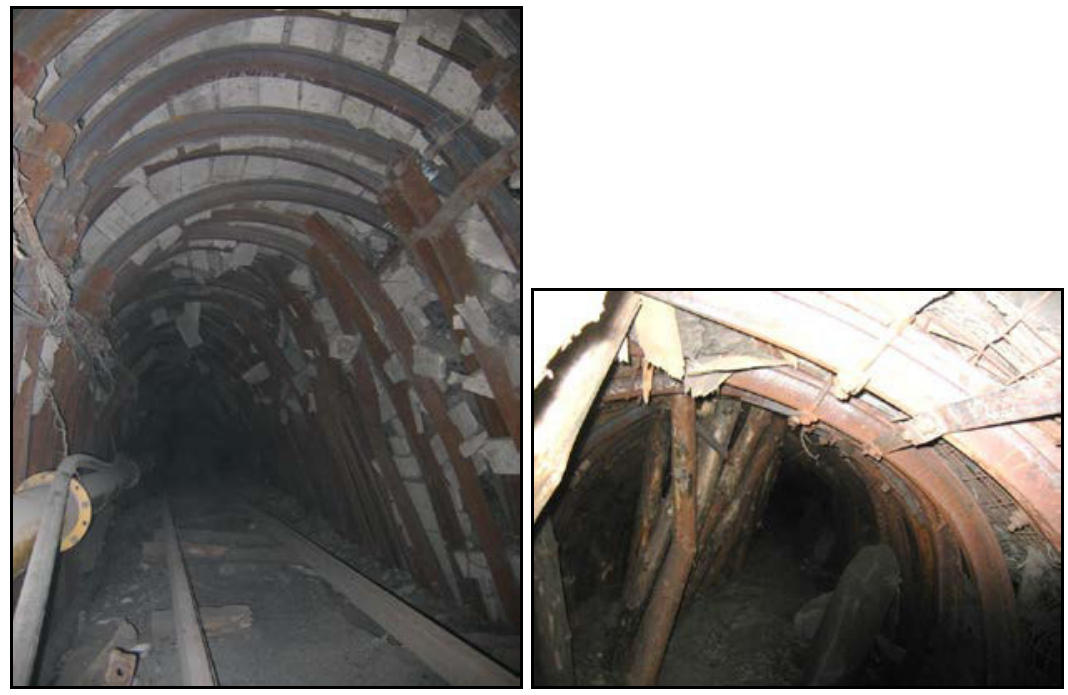

Fig. 1. Roadways with the frame supports

Instead, rock deformation can be controlled with the help of the roof bolts, which help to improve hardness and bearing capacity of the rocks. Roof bolting is widely used by many countries in their coal industries and other underground construction projects [3]. Until the 1970s, bolts with mechanical (locking) fasteners were mainly used. Development of polymer fasteners with fast setting and high strength allowed fastening the roof bolts along the entire length. Use of such roof bolts improved state of the roadways including those with weak and layered roofs. Under these conditions, mechanical roof bolts usually ruined, especially over time. In comparison with mechanical fasteners, roof bolts with polymer fasteners along the pole length (fig. 2) feature greater resistance to the lateral rock displacement. Besides, they are also less susceptible to corrosion, that significantly increases their effectiveness.

From the late ninetieth, Ukrainian miners began to use bolts with polymer fasteners. Scientific and technical aspects of these jobs were supervised by researchers of the Institute of Geotechnical Mechanics of National Academy of Science of Ukraine [4]. At that time, technology of the roof bolting was based on the then world practice. 


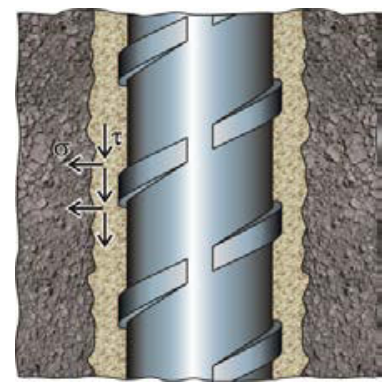

Fig. 2. Bolt with polymer fixing in the bore hole

Different normative documents specified conditions for using the roof bolts and technical requirements for the bolts and their elements, equipment and work technique. Basically, the roof support was used in the roadways with rectangular cross-section (fig. 3), and anchors were installed perpendicularly to the bedding, fig. 4 .
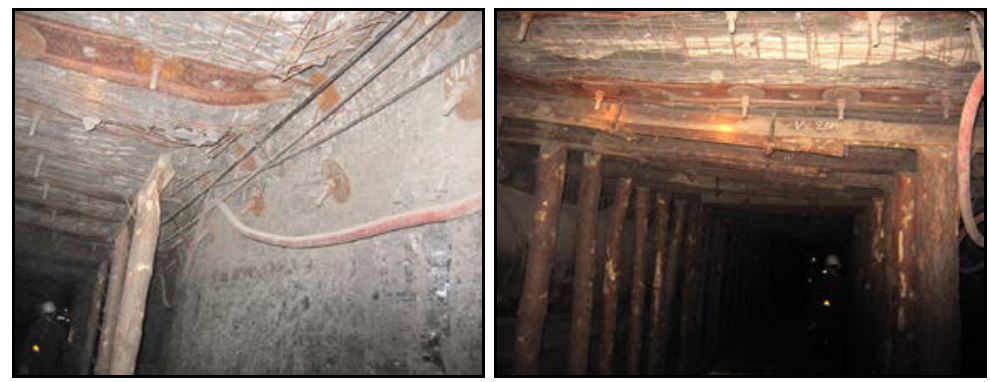

Fig. 3. The roadways with rectangular cross-section

However, in the process of accumulation of practical experience on usage of the roof bolting in the Ukrainian mines, where new equipment was implemented and, therefore, loads on the longwall increased and geological conditions were worsen, it became clear the following. Bearing capacity of the most of the known schemes and designs of the roof bolting did not give a possibility to build roadways with the working life more than 4 years. As well, the existing techniques of the roof bolting made impossible to reuse the gate roads though it was very important in view of improving the coal produce costs. 

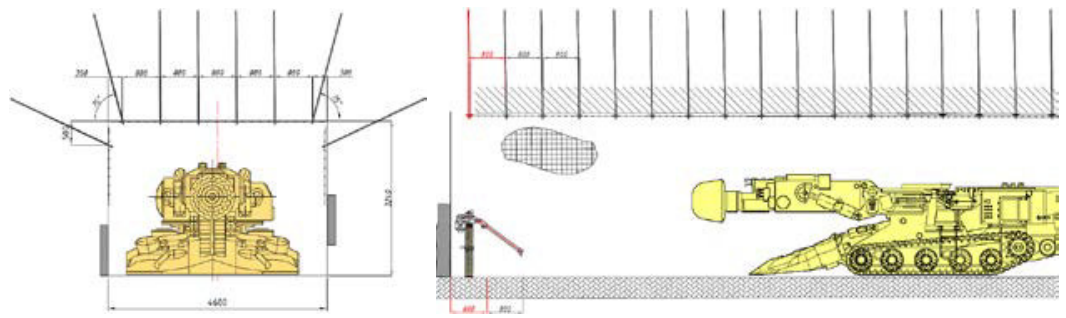

Fig. 4. Typical scheme of the roof bolting for roadways with rectangular cross-section

The reason was that geological and technical conditions in the most of Ukrainian mines were significantly more complicated than in the mines of other leading countries, which produced coal. Therefore, a simple transition of the accumulated foreign experience did not give any effective positive results. The situation demanded to study more deeply mechanism of the roof-bolt operation and to specify the spacetime laws of geomechanical processes occurred in the system "edge rock - roof bolt".

\section{Methods}

In order to study mechanism of the roof bolt operation, we designed a mathematic elastoplastic model for calculating stress state of the rocks around the roadway supported with the bolts. The process of the rocks deformation is described by equations

$$
c_{g} \frac{\partial u_{i}}{\partial t}=\sigma_{i j, j}+X_{i}(t),
$$

where $c_{g}$ - the damping coefficient, $\mathrm{kg} /\left(\mathrm{m}^{3} \cdot \mathrm{s}\right) ; u_{i}$ - the displacements, $\mathrm{m} ; t$ - time, $\mathrm{s} ; \sigma_{i j, j}$ - the derivatives of the stress tensor components along $x, y, \mathrm{~Pa} / \mathrm{m} ; X_{i}(t)$ - the projections of the external forces acting on the volume unit of a solid body, $\mathrm{N} / \mathrm{m}^{3}$.

The problem is solved in an elastic-plastic formulation. For the mathematical description of the process of rocks changeover into a disturbed state, the Mohr-Coulomb failure theory is applied. The initial and boundary conditions

$$
\begin{gathered}
\left.\sigma_{y y}\right|_{t=0}=\gamma H ;\left.\quad \sigma_{x x}\right|_{t=0}=\lambda \gamma H ;\left.\quad u_{x}\right|_{t=0}=0 ;\left.\quad u_{y}\right|_{t=0}=0 ; \\
\left.u_{x}\right|_{\Omega_{1}}=0 ;\left.\quad u_{y}\right|_{\Omega_{2}}=0,
\end{gathered}
$$


where $\gamma$ - the averaged weight of the overlying mine rocks, $\mathrm{N} / \mathrm{m}^{3}$; $H$ - the mining depth, $\mathrm{m} ; \lambda$ - the side thrust coefficient; $\Omega_{1}$ - the vertical boundaries of the outer contour; $\Omega_{2}$ - the horizontal boundaries of the outer contour.

This model took into account parameters of the roof bolts and roadway, strength and deformation properties of the rocks, as well as time and site when and where the roof bolt start working. In order to solve this problem, we applied a finite element method [5-7].

The roof bolt was simulated by the rod finite elements, washer and grab simulated by the triangle (prismatic) contact elements, and polymer fastener simulated by special contact elements. Each of the elements of the roof bolting featured certain physical and mechanical properties.

Level and character of the rock stress state change nearby with the roadway was estimated by the following parameters:

- reduced difference between the maximum and minimum components of the key stresses $\left(Q=\left(\sigma_{1}-\sigma_{3}\right) / \gamma H\right)$, this parameter characterizes difference between the stress-filed components and possible occurrence of the rock breaking;

- reduced minimal component of the principal stresses $\left(P=\sigma_{3} / \gamma H\right)$, this parameter specifies a possible type of the breaking.

\section{Results and discussion}

\subsection{Simulation of the roof-bolt operation}

In view of studying interaction between the roof bolts and rocks, we made a series of calculations.

The first step was simulation of the stress state in rocks around an unsupported roadway (fig. $5 a$ ). Result of the simulation is the basis for the further analysis.

In undisturbed massif, outside zone of mining operation influence, rocks are in the state of triaxial compression.

Vertical component of the stress field is determined by the weight of the overlying rock mass, and two horizontal components are determined by the lateral arching of the rocks. 
$a$

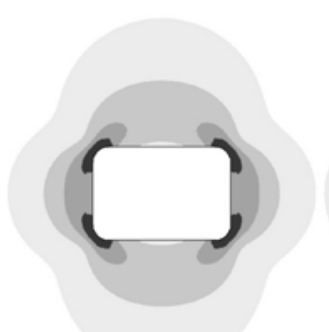

$b$

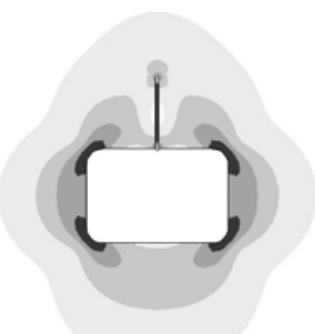

$c$

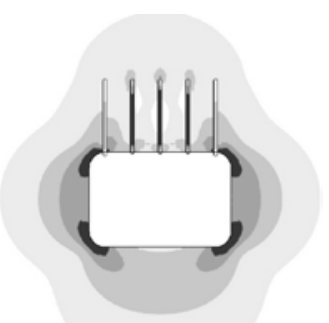

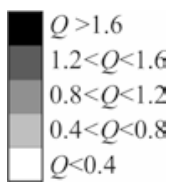

Fig. 5. Formation of the rock-bolt support and canopy in the roadway roof. Distribution of parameter $Q$ values: $a$ - the roadway with no support; $b$ - with 1 roof bolt; $c$ - with 5 roof bolts

Since coefficients of lateral arching are close to 1, state of the rocks in their natural occurrence is close to uniform compression. Difference between principal stress components in undisturbed massif is usually close to zero. That is why, regardless of the depth of the rock bedding, process of the rock breaking does not occur. This state of rocks is also observed in the massif with the roadway, but at some distance from it. At driving the roadway within zone of its influence, stress field in the rocks changes. Minimum component converges to zero, and maximum component increases and becomes greater than the maximum component in the undisturbed massif. In the edge zone, the unsupported rocks are deformed and their breaking is developed, fig. $5 a$.

When one bolt is installed, a certain volume of the roof rocks connected with the bolt is kept from displacing. With the course of time, rocks in zone around the bolt do not unloaded and are still in the compressed state. At a certain distance from the bolt, deformation processes are developed in the rock mass by the same pattern as in the roadway with no bolts. It is possible to specify this zone around the bolt as a support due to its function, fig. $5 b$.

A system consisting of 5 bolts (fig. $5 c$ ) prevents the edge rocks of the roof from shifting into the roadway and keeps the edge massif in a compressed state. As you can see, size of area with triaxially compressed rocks in the roadway roof is increased significantly (in com- 
parison with the roadway with one bolt installed). Now it covers most part of the reinforced space.

\subsection{New design of the roof bolting}

Roof bolting is a space system of the roof bolts fastened in the bore holes. The key target of the installed bolt system is to arrange such layout of the bolts, which can ensure maximally effective interaction between supports created by the bolts. How to improve efficiency of interaction between the rock-bolt supports? To increase density of the bolt installation? But when parallel bolts are installed very close to each other it can trigger crack formation between them. Under certain geological conditions, when the bolts are installed vertically, a rock mass can be divided into blocks. And we know cases when such blocks have fell down into the roadways, fig. 6 .
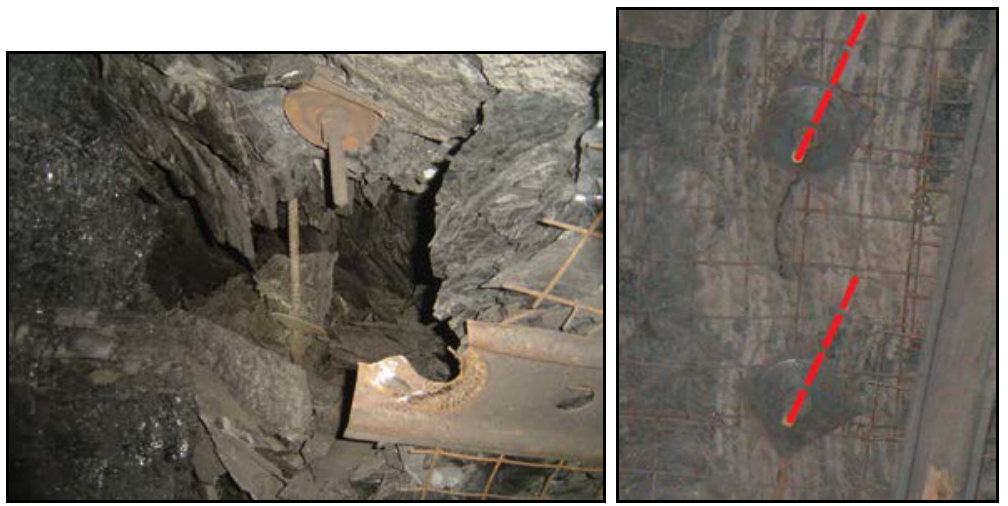

Fig. 6. Close setting of parallel roof bolts

The most promising method for improving interaction between the bolts is such their layout in the space, which would keep the rocks of the edge massif in a triaxially compressed state. As tests of the samples show, even a slightly increased lateral backup increases ultimate strength by 1.5-2.5 times.

We have analyzed results of our long-term observations and laboratory, computational and mine experiments conducted in more than 30 coal mines of Ukraine and established on their basis a concept of the rock-bolt support interaction, according to which supports unite into a single construction that can resist rock pressure (fig. 7). We also have solved a problem of how to improve efficiency of interaction between the rock-bolt supports $[8,9]$. 


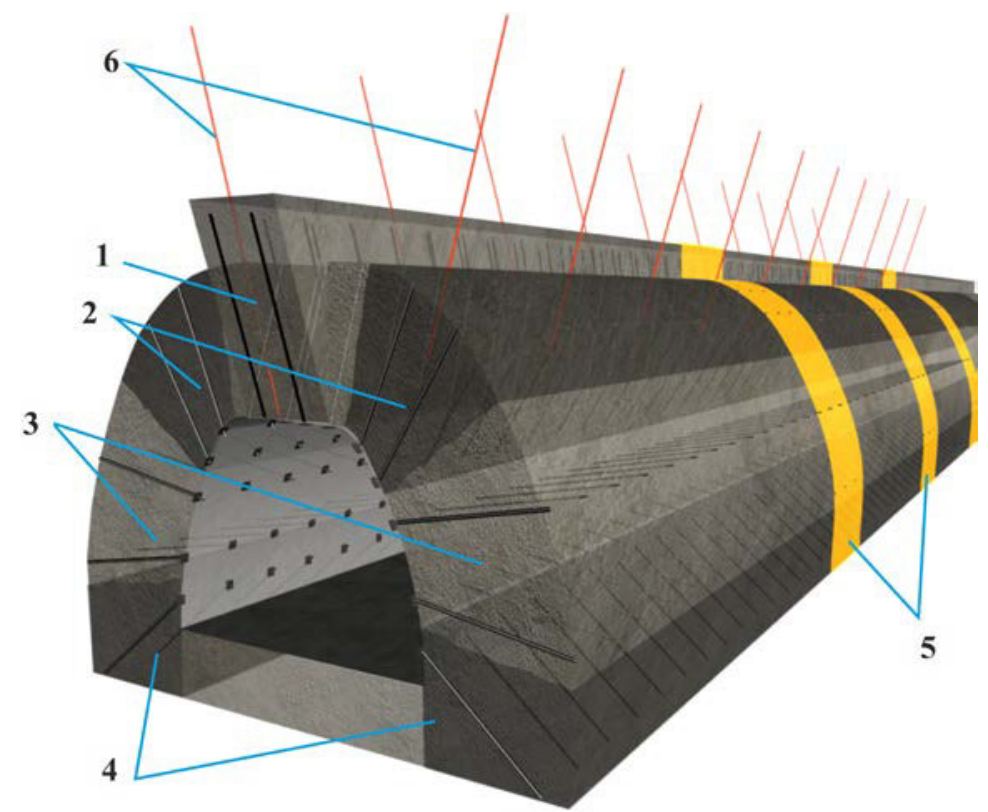

Fig. 7. Formation of the rock-bolt blocks in the structure of the rock-bolt canopy:

1 - is a load-bearing part of the canopy; 2 - is a backing-up part of the canopy; 3 are supports of the canopy; 4 - is a base of the structure; 5 - is an element of the rock-bolt structure which we call a "bridge"; 6 - cable bolts

Functions of elements in the roof-bolting construction [10].

The load-bearing part of the canopy (fig. 7) counteracts deformations of the roof rocks and their displacement into the roadway. This element is the main and mandatory one. It is located in the central part of the roof along the entire roadway and is formed by the bolts in amount from 2 to 5 depending on the size of the roadway cross section and required capacity of the construction. This structural element can be reinforced by the deep rope bolts.

The backup part (fig. 7) takes the load from the load-bearing element of the canopy and transmit it to the support. This part is also needed for controlling life period of the construction depending on the roadway operation. This backup part consists of two elements located on both sides of the load-bearing part in the construction, not necessarily symmetrically about the axis of the roadway. Differences 
in the pattern of the backup part formation on each side of the roadway can be caused by:

- inclination of the coal seam and rock layers;

- cleavage and direction of natural fracturing;

- technological requirements for the winning operations (roadway to be closed or stored for reuse);

- coal-cutting with the goaf.

The backup part is a mandatory element of the roof-bolting construction and should consist of 1 to 4 steel-polymer bolts.

Supports of the canopy (fig. 7) transmit load from the canopy to the base. Load-bearing part of the construction is located in central part of the roadway walls, in the coal seam, in the rock above or below it. If the roadway walls are represented by the hard rocks, then in areas with partial supporting, this element is not mandatory. The load-bearing part is represented by two elements that are not always symmetrical about the axis of the roadway.

Quantity of bolts in the structural supports depends on the:

- roadway height;

- coal seam thickness;

- hardness of the coal seam and enclosing rocks;

- roadway function;

- roadway life.

Usually, number of bolts per one support does not exceed 4.

The base of the construction (fig. 7) facilitates increasing of stability of the roadway wall and decreasing of the floor heaving. It is located in the bottom of the roadway walls provided that hard rocks in the roadway walls are not obligatory element for the roof-bolting construction. The base consists of 1 or 2 steel-polymer bolts (for the cases when coal seam is located in the bottom of the roadway section, plastic or wooden bolts can be used).The floor bolts are inclined downward at an angle of $10-25^{\circ}$ and can cross the floor line.

The element of the rock-bolt construction, which we call a "bridge" (fig. 7). On the scheme, it is marked by yellow. This element is a sector of the roadway with the higher stiffness thanks to the additionally set bolts. The "bridges" prevent the edge rock mass from breaking due to the released strain energy, which is accumulated with each elongation of the roadway. Staggering of such sectors makes 
possible to control the roadway stability, restore the needed safety factor and reduce expenses for the roadway exploitation.

The element "protective bridge" consists of several consecutive rows of the roof bolts with more powerful structure than the basic support.

Length of each of the protective jumpers and distance between them are determined by mining and geological conditions, function of the roadway and its service life. Usually, length of the bridge is 4-5 rows, and distance between them is $20 \mathrm{~m}$. With the scheme with full roof bolting canopy, sectors are supported by the bolts in the following areas:

- at the beginning and at the end of roadway with roof bolting (transitional sections);

- with changed geometry of the roadway cross section;

- with geological disturbances;

- in conjugate areas with other roadways;

- with other roadway underworking or overworking.

Angle of the bolt inclination in the elements is determined by the type of the construction: simple, reinforced, powerful. For the simple construction, bolts are installed in the plane of the cross section perpendicular to the axis of the roadway.

For the reinforced one some bolts are installed with inclination towards the face at an angle of $70-75^{\circ}$. For the powerful construction, one part of the bolts is installed with inclination towards the face at an angle of $70-75^{\circ}$ and another part is installed with inclination backwards, towards the roadway mouth, at an angle of $70-75^{\circ}$. Such bolt inclination significantly increase interaction between the bolts in comparison with traditional schemes of unidirectional reinforcement of the edge rock massif.

In order to test the roof-bolting constructions in the mine conditions, we developed "The Program and Methodology for Industrial Testing of the Roof-Bolt Constructions in the Main Workings at the Pavlogradugol Mine".

As a result of the tests, operability of the roof bolt and its elements was validated, and indicators for efficiency and safety of its use were determined (fig. 8). 


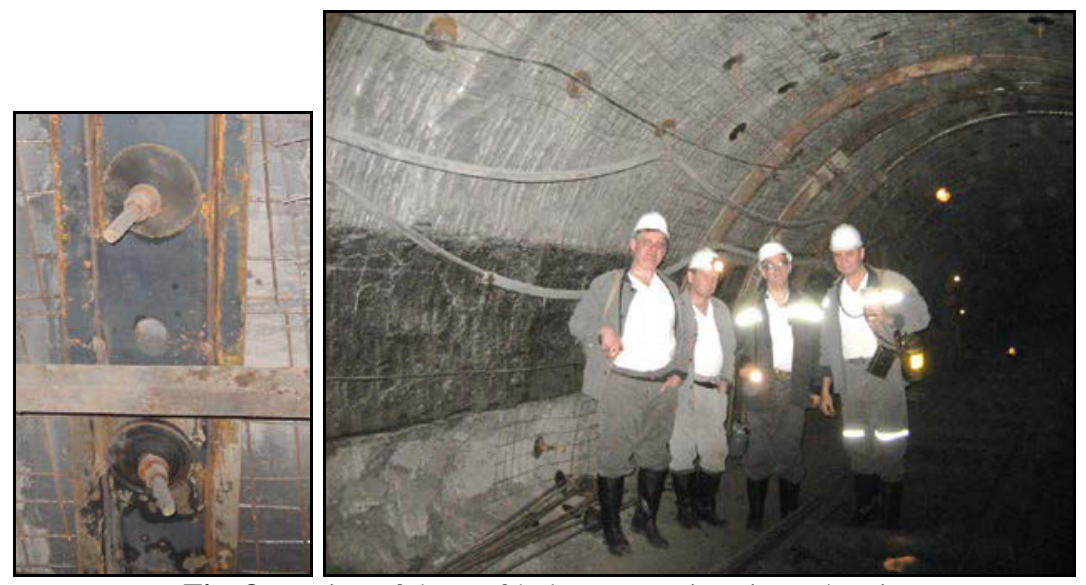

Fig. 8. Testing of the roof-bolt constructions in coal mains

\subsection{The technology of the bearing-bolt supporting}

Thus, the technology of the roof bolting was further developed [11], fig. 9, and range of its application was essentially expanded thanks to the following principles of the support setting:

- firstly, implementation of the system of bolts, which are set inclined along the roadway axis, and which improve interaction between the rows of the bolts and give a possibility to form the rockbolt constructions;

- secondly, structural division of the of rock-bolt canopy into blocks (the bolts are installed in groups). It makes possible to maintain stability of the roadway as a whole system thanks to the safety displacement of the blocks relatively to each other;

- thirdly, arrangement, from time to time, of the areas with enhanced structural stiffness along the whole length of the roadway.

The technology of the bearing-bolt supporting is used for retaining the enclosing rocks in undisturbed and monolithic state, close to the state of a uniform compressed undisturbed rock massif. To this end,

- time period between extraction of coal-rock mass from the face and setting of the roof bolts and

- distance between the face and the first row of roof bolts should be reduced to a minimum. 
In this case, edge rocks in the unsupported part of the roadway roof and walls have no time for getting unloaded from the rock pressure and their solidity will be fully preserved.

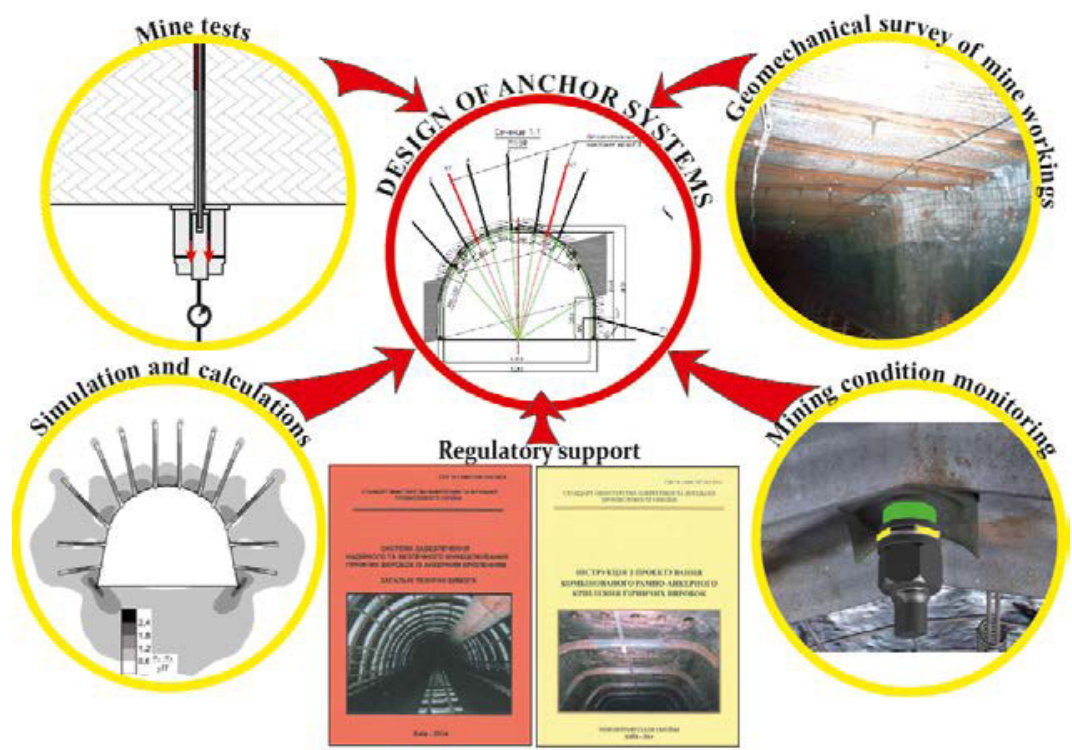

Fig. 9. Elements of the technology of the bearing-bolt supporting

Technological cycle of installation of the roof bolt construction consists of preparatory works and support setting for the roadway roof and walls. In order to reduce duration of this cycle, the following aspects were optimized:

- sequence of technological operations performed by the miners;

- the required amount of materials and equipment;

- layout of materials, equipment and tools at the workplace in order to minimize the length of route covered by the miner during the shift;

- devices for quick and accurate execution of technological operations (a template for observing the row spacing and inclination angles when drilling holes; a template for marking on the ground and saving the lower point of the drilling rig installation).

The support and scheme of the bolt setting are calculated basing on the requirement to exclude rock falling around the roadway. Bearing capability of the rock-bolt supports is determined depending on 
geological conditions of the mining operations, characteristics of the bolt strength and the bolt fastening in the bore hole. An optimal quantity of the bolts and scheme of the bolt setting are calculated in terms of the support resistance required for blocking displacement of the roadway contour.

One of the key requirements of the technology is to set the roof bolts into the enclosing rock mass, which is not unloaded from the rock pressure. In this case, the support, just after having been set, immediately starts working on resisting the forces of the rock pressure. The edge rock mass maximally saves its natural monolithic state. If not, the bolts will just "sew together" the stratificated roof rocks.

\subsection{Duration of the roof bolt setting taken into account while determining technological parameters}

As well, we developed a new method for calculating parameters of the stress-strain state of the rocks and construction of the rock-bolt bridge for technological cycles of setting the rows of the roof bolts. This method takes into account the rock unloading during the cycle and a moment of time when the row of the roof bolts start to operate $[12,13]$. In order to study influence of the speed of the roadway driving and distance between the site of the bolt setting and working face on the roadway stability, we calculated several technological schemes (fig. 10, 11).

$a$

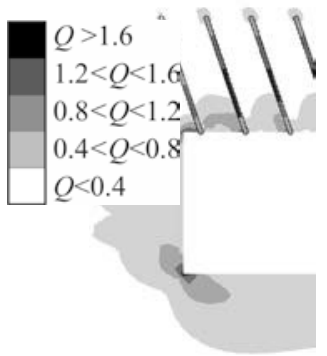

$b$

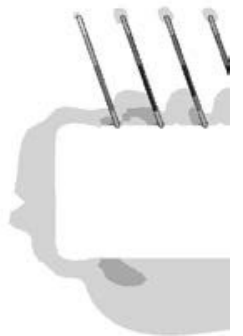

C

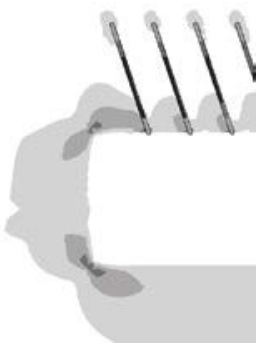

Fig. 10. The stress field $(Q)$ changing during technological cycle of the roof bolt setting, distance between the site of the bolt setting and working face $-0.3 \mathrm{~m}: a$ before the face driving; $b$ - on the next iteration after the face driving; $c$ - in 30 iterations 
Speed of the roadway driving was changed in the range of from 5 to $40 \mathrm{~m}$ per day. Distance between the site of the bolt setting and working face was changed within the range of $0.3-5 \mathrm{~m}$.

$a$

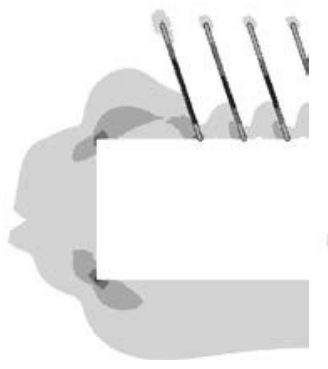

$b$

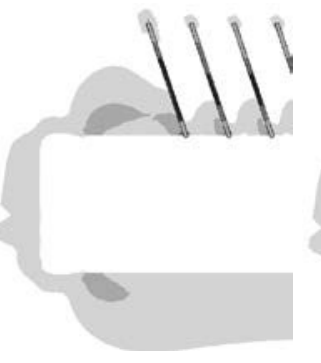

$c$

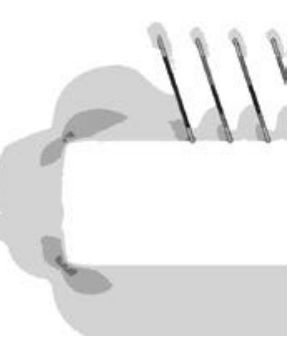

Fig. 11. The stress field $(Q)$ changing during technological cycle of the roof bolt setting, distance between the site of the bolt setting and working face $-1.9 \mathrm{~m}$ :

$a$ - before the face driving; $b$ - on the next iteration after the face driving;

$c$ - in 30 iterations

Figure 12 shows diagrams of the roof displacement when the bolts were set at distance $0.3,1,2$ and $5 \mathrm{~m}$ from the face at speed of the roadway driving 10 meters per day. In the first variant, the roof bolt is set at distance of $0.3 \mathrm{~m}$ from the face. As the face is further driven the bolts are loaded and prevent the rock from displacing into the inside of the roadway. When the bolts are set at a longer distance from the face with the lag, the edge rock mass can easily displace during certain period of time and become unloaded.

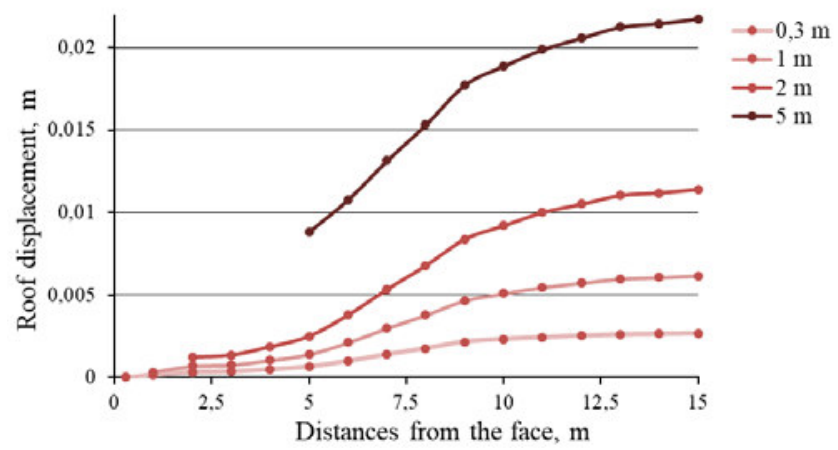

Fig. 12. Roof displacement with the bolts set at different distances from the face 
Thereby, the bolts will be set into the disturbed rocks or, in case of the soft rocks with low tensile strength, into the broken rocks.

\subsection{Reuse of the preparatory roadways}

Special difficulties present maintenance of the roadways for their further reuse while mining an adjacent longwall [14, 15]. Application of bearing-bolt supports showed good results for these complicated conditions as well [16]. For example, the reinforced construction of the roof bolting with the powerful protective bridges was used in the mother entry 585 of the Yubileynaya Mine (fig. 13).

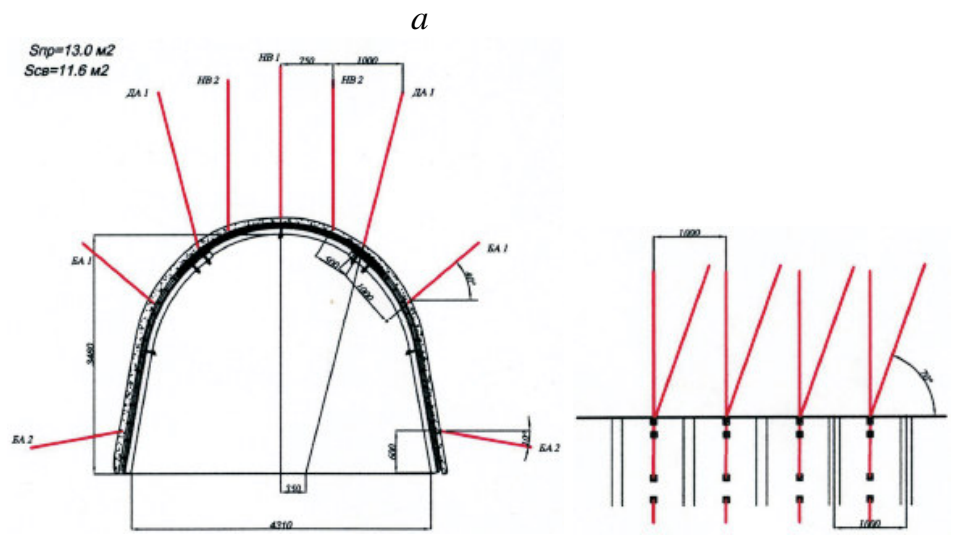

$b$
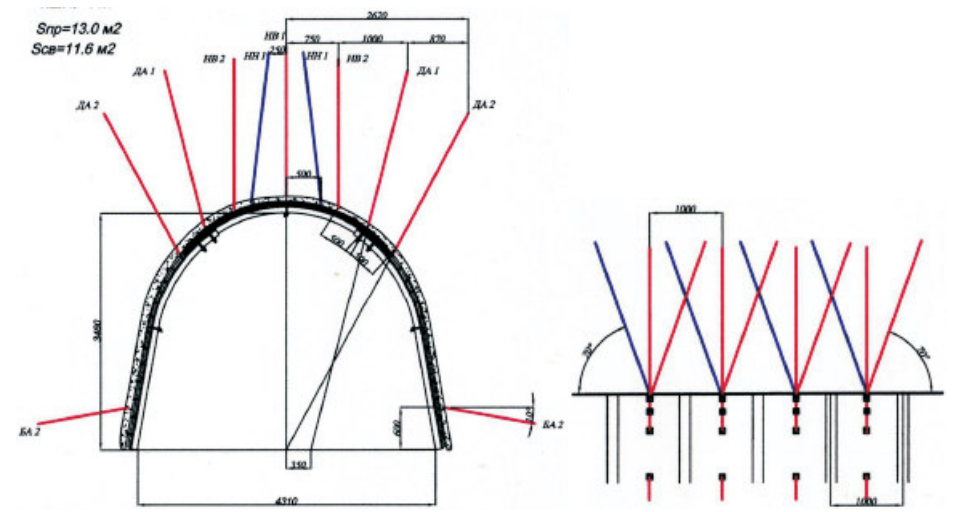

Fig. 13. Combined frame-bolt support with reinforced roof bolting in the roadway 585 of the Yubileynaya Mine: $a$ - Simple sector; $b$ - sector "bridge" 
The roadway had an arch cross section. It was kept in operation after the first and the second longwalls had been mined out and later. Results of monitoring showed satisfactory stability of the roadway at all of the stages, fig. 14. The roof was not broken, it just sagged as a single block with turning, first, towards one side and then - towards another. Periodical reinforcement of the bridges helped to restore stability of the roadway and not to accumulate negative affect of the rock pressure with each elongation of the roadway.

$a$

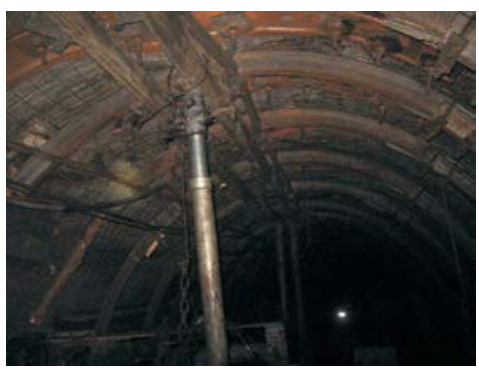

$b$

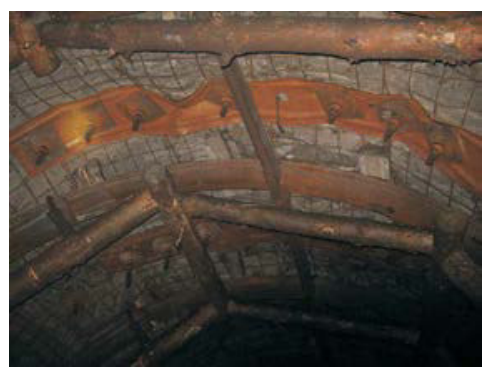

Fig. 14. Condition of the roadway 585 of the Yubileynaya Mine: $a-10 \mathrm{~m}$ to face end; $b-60 \mathrm{~m}$ after the face

\subsection{Influence of the roof bolting on the rock permeability}

One more advantage of the bearing-bolt supporting must be mentioned, which is also best for driving roadways through the gasbearing coal seams and rocks and undermining of the water-flooded rocks. Results of solving the problems of elastoplastic deformations and fluid filtration were confirmed by data from the mines and have showed the following $[17,18]$.

In the roadway where roof is supported by the technology of the bearing-bolt supporting, an impermeable rock-bolt canopy is formed. This canopy prevents escaping of methane from the gas sources in the roof into atmosphere of the roadway. When density of the bolt setting is increased up to 1.1 bolt per meter, average speed of methane filtration and discharge decreases by 75 percent (fig. 15).

Application of roof bolting for the blocks in the roadway driven through the gas-bearing coal seam keeps the seam and enclosing rocks in stable state, and blocks processes of crack formation and coal 
pressing-out. Each of the bolts, set into the wall of the roadway, decreases filtration permeability by 20-30 percent. Such effect essentially decreases volume of methane escaping from the coal seam during mining and exploitation of the roadway. The bolts which are set in the bottom of the roadway walls prevent the walls from breaking and decrease zone with inelastic deformation in the roadway floor and, consequently, diminish floor heaving and filtration permeability.

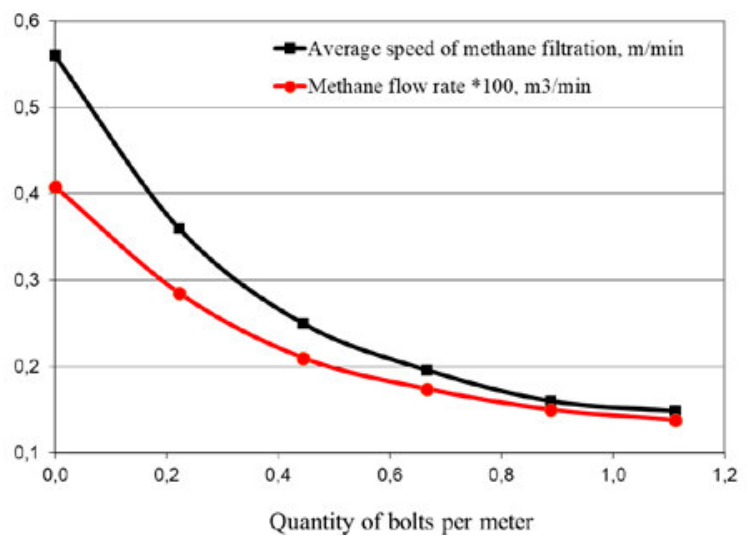

Fig. 15. Change of speed of methane filtration and consumption depending on density of the bolt setting in the roadway roof

Therefore, the roof bolting can be considered as a technological method for decreasing methane content in the roadways and water inflow during undermining of the water-flooded rocks [17-20].

\section{Conclusions}

Basing on the research findings, we have developed and approved a normative document, which regulates parameters for the technology of the bearing-bolt supporting. We also have developed an album with typical constructions, which regulates choice of the schemes for the roof bolt setting in typical mining, geological and technological conditions of the roadway drivage.

The technology of the reinforced and powerful bearing-bolt supporting designed by our Institute of Geotechnical Mechanics was successfully realized in practice in 52 Ukrainian mines for driving more than 700 preparatory roadways and permanent workings. This ap- 
proach helped to achieve stable state of the roadways under the complicated mining and geological conditions and obtain good economic effect thanks to the cut expenses spent to the roadway supporting and repair.

However, the most weighty contribution of the roof bolting technology into cutting costs of coal production is, to our mind, higher rates and essentially better safety of the winning operations.

Thanks to the stable, almost unstressed state of the face end, necessity in setting additional supports falls down, and time period needed for the end operations during the face mining becomes essentially shorter. Besides, our technology makes it possible to use effectively any powerful mining machines and significantly speed up rate of the face mining.

References

1. Vinogradov, V.V. (1989). Geomechanics of massif condition control near mining. Kiev: Naukjva Dumka [in Russian].

2. Litvinsky, G.G., Gajko, G.I. \& Kuldyrkaev, N.I. (1999) Steel frame supports of mine workings. Kiev: Tekhnika [in Russian].

3. Bulat, A.F. \& Vinogradov, V.V. (2002). Oporno-ankernoe kreplenie gornyih vyirabotok ugolnyih shaht. Dnepropetrovsk: Vilpo [in Russian].

4. Bulat, A.F., Popovich, I.M., Vivcharenko, J.V. \& Krukovskiy, O.P. (2014). Technology of bolting of mine workings at mines in Ukraine: state and prospects. Coal of Ukraine, 2, 3-7 [in Ukrainian].

5. Zienkiewicz, O.C., Taylor, R. L. \& Zhu J. Z. (2013). The Finite Element Method: Its Basis and Fundamentals, Butterworth-Heinemann.

6. de Borst, R., Crisfield, M.A., Remmers, J.J.C. \& Verhoosel, C.V. (2012). Non-linear finite element analysis of solids and structures, John Wiley \& Sons.

7. Kovalevska, I., Symanovych, G. \& Fomychov, V. (2013). Research of stress-strain state of cracked coal-containing massif near-the-working area using finite elements technique. Annual Scientific-Technical Collection-Mining of Mineral Deposits, 159-163.

8. Vinogradov, V.V., Krukovskyi, O.P. \& Khvorostian, V.A. (2010). The anchor bolting technology in Ukraine. Geotechnical mechanics, 88, 170-179 [in Ukrainian]. 
9. Krukovskiy, O.P., Khvorostian, V.A. \& Krukovskaia, V.V. (2013). Technology of supporting bolting of mine workings. Coal of Ukraine, 2, 13-16 [in Russian].

10. Vinogradov, V.V. \& Krukovskyi, O.P. (2011). Rock-anchor elements of the force support-anchor fastening. Geotechnical mechanics, 93, 3-18 [in Russian].

11. Bulat, A.F. (2014). Advanced technologies of mine workings supporting in coal mines of Ukraine. Visnyk of the NAS of Ukraine, 1, $74-79$ [in Ukrainian].

12. Krukovskyi, O.P. (2011). Modelling changes of stress-strain state of solid edge during the distance of working face of mine workings. Problems of computational mechanics and strength of structures, 17, 175-181 [in Russian].

13. Krukovskyi, O., Bulich, Y. \& Zemlianaia, Y. (2019). Modification of the roof bolt support technology in the conditions of increasing coal mining intensity. Essays of Mining Science and Practice 2019. E3S Web of Conferences, 109, 00042. doi.org/10.1051/e3sconf/201910900042

14. Shashenko, A.N., Khozyaykina, N.V. \& Smirnov, A.V. (2017). Geomechanical and economic assessment of the width of protection arrangement at re-use of the development workings in the coal mines. Occupational Safety in Industry, 8, 16-20 [in Russian].

15. Tereshchuk, R.M., Khoziaikina, N.V. \& Babets, D.V. (2018). Substantiation of rational roof-bolting parameters, Naukovyi Visnyk Natsionalnoho Hirnychoho Universytetu, 1, 19-26.

16. Krukovskyi, O.P. (2015). Change of stress field around the mine working with different types of support which conservated after wall face driving. Geote?hnical mechanics, 121, 39-47 [in Russian].

17. Krukovska, V.V. (2015). Simulation of coupled processes that occur in coalrock massif during mining operations. Geotechnical Mechanics, 121, $48-99$ [in Russian].

18. Krukovskyi, O.P., Krukovska, V.V. \& Vynohradov, Y.O. (2017). Mathematical modeling of unsteady water filtration in anchored mine opening. Mining of Mineral Deposits, 11(2), 21-27 [in Russian].

19. Vynohradov, V.V., Krukovskyi, O.P. \& Krukovska, V.V. (2007) Application of roof bolting constructions as technological way of the methane content decrease in the mine workings. Problems of Computational Mechanics and Strength of Structures, 11, 30-37 [in Russian].

20. Krukovska, V. \& Vynohradov, Y. (2019). Water stability influence of host rocks on the process of water filtration into mine working with frame and roofbolting support. Essays of Mining Science and Practice 2019. E3S Web of Conferences, 109, 00041. doi.org/10.1051/e3sconf/201910900041 